\title{
The TEL/ET V 6 gene is required specifically for hematopoiesis in the bone marrow
}

\author{
Li Chun Wang ${ }^{1,6}$ Wojciech Swat, ${ }^{3}$ Yuko Fujiwara, ${ }^{1,5}$ Laurie Davidson, ${ }^{2}$ Jane Visvader, ${ }^{1}$ Frank Kuo, ${ }^{3}$ \\ Fred W. Alt, ${ }^{2,5}$ D. Gary Gilliland, ${ }^{4,5}$ Todd R. Golub, $^{1}$ and Stuart H. Orkin ${ }^{1,5,7}$ \\ Departments of ${ }^{1}$ Pediatrics, ${ }^{2}$ Genetics, ${ }^{3}$ Pathology, and ${ }^{4} \mathrm{M}$ edicine, Harvard Medical School, and ${ }^{5} \mathrm{H}$ oward Hughes M edical \\ Institute, Boston, M assachusetts 02115 USA
}

The TEL (translocation-Ets-leukemia or ETV6) locus, which encodes an Ets family transcription factor, is frequently rearranged in human leukemias of myeloid or lymphoid origins. By gene targeting in mice, we previously showed that $\mathrm{TEL}^{-1-}$ mice are embryonic lethal because of a yolk sac angiogenic defect. TEL also appears essential for the survival of selected neural and mesenchymal populations within the embryo proper. Here, we have generated mouse chimeras with $\mathrm{TEL}^{-1-}$ ES cells to examine a possible requirement in adult hematopoiesis. Although not required for the intrinsic proliferation and/or differentiation of adult-type hematopoietic lineages in the yolk sac and fetal liver, TEL function is essential for the establishment of hematopoiesis of all lineages in the bone marrow. This defect is manifest within the first week of postnatal life. Our data pinpoint a critical role for TEL in the normal transition of hematopoietic activity from fetal liver to bone marrow. This might reflect an inability of $\mathrm{TEL}^{-1-}$ hematopoietic stem cells or progenitors to migrate or home to the bone marrow or, more likely, the failure of these cells to respond appropriately and/or survive within the bone marrow microenvironment. These data establish TEL as the first transcription factor required specifically for hematopoiesis within the bone marrow, as opposed to other sites of hematopoietic activity during development.

[Key Words: TEL gene; hematopoiesis; leukemia]

Received April 23, 1998; revised version accepted June 2, 1998.

Hematopoiesis is the process by which blood cells of distinct lineages (erythrocytes, B and T Iymphocytes, neutrophils, monocyte/macrophages, mast cells, and megakaryocytes) are produced from pl uripotent hematopoietic stem cells (HSCs) (Orkin 1996). HSCs lie at the top of the hierarchy and give rise to progenitor cells that exhi bit varying developmental potential s. Options available to progenitors become restricted progressively until differentiation al ong a single pathway takes place. Blood cell formation is initiated early during vertebrate embryogenesis. The first cells produced, embryonic (or primitive) erythrocytes, arise within the blood islands of the extraembryonic yolk sac at embryonic day 7.5 (E7.5). By E11.5, hematopoiesis shifts to the fetal liver, where adult (or definitive) red cells, as well as cells of other lineages, first appear. The site of origin of HSC s has been less certain. Whereas it was previously accepted that HSC s and progenitors migrate from the yolk sac to the fetal liver during devel opment, more recent studies relying on cell transplantati on to reconstitute hematopoiesis in adult recipients assign an intraembryonic source for

6Present address: Biogen, Inc., Cambridge, Massachusetts 02142 USA. ${ }^{7}$ Corresponding author.

E-MAIL Orkin@rascal.med.harvard.edu; FAX (617) 355-7262. definitive (adult) hematopoi esis within the intraembryonic para-aortic splanchnopl eura and aortic-gonadal-mesonephros (AGM) regions (Godin et al. 1993; M edvinsky et al. 1993; Medvinsky and Dzierzak 1996). HSCs arising in these areas are bel ieved to migrate to and colonize the fetal liver and spleen. The presence of multipotential progenitors in the blood of E10 embryos suggests that migration and colonization are mediated via the circulation (Delassus and Cumano 1996). A unique origin of HSCs is challenged by recent evidence demonstrating long-term repopulation by yolk sac progenitors as assayed by reconstitution of fetal recipient animals (Y oder et al. 1997). Thus, the devel opment of a stable, functioning hematopoietic system reflects compl ex processes involving cellular differentiation, as well as temporal and spatial control of migration, homing, proliferation, and survival of HSCS.

Regulation takes place at multiple levels to ensure proper blood cell development. Cytokines and their cognate receptors medi ate signal s that participate directly or indirectly in the proliferation, differentiation, or survival of HSC and progenitor cells (see Veiby et al. 1997). Ultimately, these processes are mediated by transcription factors that serve to establish cellular patterns of gene expression (Orkin 1996). In vivo requirements for tran- 
scription factors exhibiting hematopoietic or lineage-restricted pattterns of expression have been established by gene targeting studies (see Shivdasani and Orkin 1996).

A mong transcriptional proteins essential for aspects of hematopoiesis, several were discovered by virtue of chromosomal translocations associated with human leukemias. These include the SCL/tal-1, Rbtn2/ Lmo2, MLL1, and AML-1 genes (Yu et al. 1995; Okuda et al. 1996; Porcher et al. 1996; Robb et al. 1996; Wang et al. 1996). Another presumed transcription factor involved in leukemia is encoded by the (TEL) (translocation-Ets-leukemia or ETV6) locus (Golub et al. 1994). The involvement of the TEL gene in leukemia is particularly interesting in that different translocations lead to the production of various chimeric proteins, which are associated specifically with distinct forms of the disease (see Golub et al. 1997). Fusion of the ol igomerization (or pointed) domain of TEL with the platel et-derived growth factor receptor- $\beta$ (PDGF $\beta R$ ) chain or with c-Abl leads to constitutive activation of their tyrosine kinases in the pathogenesis of chronic myelomonocytic leukemia (Golub et al. 1994; Papadopoulos et al. 1995; Golub et al. 1996). Fusion of this region with the catalytic domain of the Janus family kinase, JAK2, is associated with various leukemias depending on the precise chimera generated (Lacronique et al. 1997; Peeters et al. 1997). Finally, the fusion of the oligomerization domain to the DN A-binding and transactivation regi ons of the runt-rel ated $A M L-1 / C B F \alpha 2$ protein is commonly seen in childhood acute pre-B-cell Iymphoblastic leukemia (Golub et al. 1995; Romana et al. 1995), and confers a favorable prognosis (M cLean et al . 1996; Shurtleff et al. 1995). TEL-AM L1-associated leukemia is unique in that the normal TEL allele is consistently absent (Sato et al. 1995; Stegmaier et al. 1995; Kim et al. 1996; M CLean et al. 1996; Raynaud et al. 1996). Loss of heterozygosity suggests that functions of the normal TEL protein may retard or block the development (or progression) of leukemia. This observation predicts a role for TEL itself in some aspect(s) of blood cell formation.

As shown by gene targeting, TEL function is required for viability of the developing mouse. TEL ${ }^{-1-}$ embryos die at E11.5 because of a failure in maintenance of the devel oping vascular network in the yolk sac (Wang et al. 1997). In addition, apoptosis occurs in selected regi ons of the embryo. We showed previously that TEL is not required for production of embryonic red cells in the yolk sac, or for in vitro colony formation by definitive hematopoietic progenitors. Although excluding TEL as an essential regulator of the intrinsic differentiation programs of hematopoietic cells, these observations did not address functions in adult hematopoiesis in vivo.

To investigate the role of TEL in fetal liver or bone marrow hematopoiesis within the context of an intact animal, we examined the development of all blood lineages in chimeric mice generated in both wild-type and recombinase-activating-2 gene (RA G-2) ${ }^{-1-}$ backgrounds (Chen et al. 1993). Here, we demonstrate that, al though dispensable for fetal liver hematopoiesis, TEL is specifically required for bone marrow hematopoiesis, as early as the immediate postnatal period. Our findings raise several possible mechanisms by which TEL functions in hematopoiesis, and have implications for the consequences of TEL loss in childhood pre-B-cell leukemia.

\section{Results}

TEL is expressed in hematopoietic tissues and cell lines

TEL RNA transcripts are expressed widely in the early embryo and adult mouse (Wang et al. 1997). We used RNA in situ hybridization to assess TEL expression at midgestation. As compared with other tissues except the lung, TEL transcripts are expressed highly in the fetal liver and thymus at E14.5 (Fig. 1A,B). TEL mRNAs are also detectable by $\mathrm{N}$ orthern blotting in cell lines representative of various blood lineages and developmental stages (Fig. 1C). Thus, TEL appears to be relatively abundant in hematopoietic cells.

Selection for G418-resistant hematopoietic colonies demonstrates that $\mathrm{TEL}^{+1-}$ and $\mathrm{TEL}^{-1-}$ embryonic stem cells contribute to definitive lineages of chimeric mice at the yolk sac stage

Prior analysis of $\mathrm{TEL}^{-1-}$ embryos revealed normal erythropoiesis in the yolk sac and the presence of both ery-
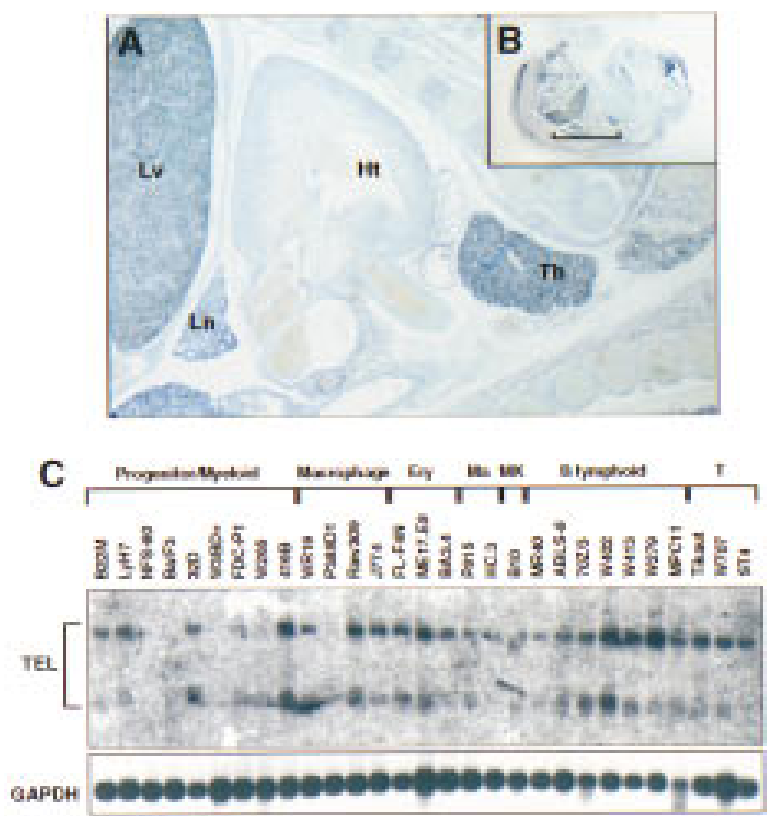

Figure 1. TEL mRNAs are expressed in hematopoietic tissues and cell lines. (A,B) In situ hybridization of TEL transcripts was performed on E14.5 paraffin-embedded embryos as described previously (Wang et al. 1997). (Th) Thymus; (Ht) heart; (Lv) liver; (Ln) lung. (C) N orthern blot analysis of poly(A)+RN A isolated from the indicated murine cell lines. Hybridization with TEL CDNA probes is shown above. Hybridization with GAPDH CDNA as a control is shown below. (M a) Mast cells; (MK) megakaryocytes; (T) T Iymphoid. 
throid and myeloid colonies in col ony assays of yolk sac progenitors (Wang et al. 1997). Such in vitro colonies obtained from the mid-yolk sac arise from definitive progenitors (Kennedy et al. 1997). To circumvent the early lethality of $\mathrm{TEL}^{-1-}$ embryos and examine a potential role for TEL in definitive hematopoi esis, we analyzed chimeras made by injection of $\mathrm{TEL}^{+-}$and $\mathrm{TEL}^{-1-}$ embryonic stem cells into wild-type C57BL/ 6 blastocysts. To distinguish host and ES-derived hematopoi etic progenitors, we took advantage of the presence of an active neomy-

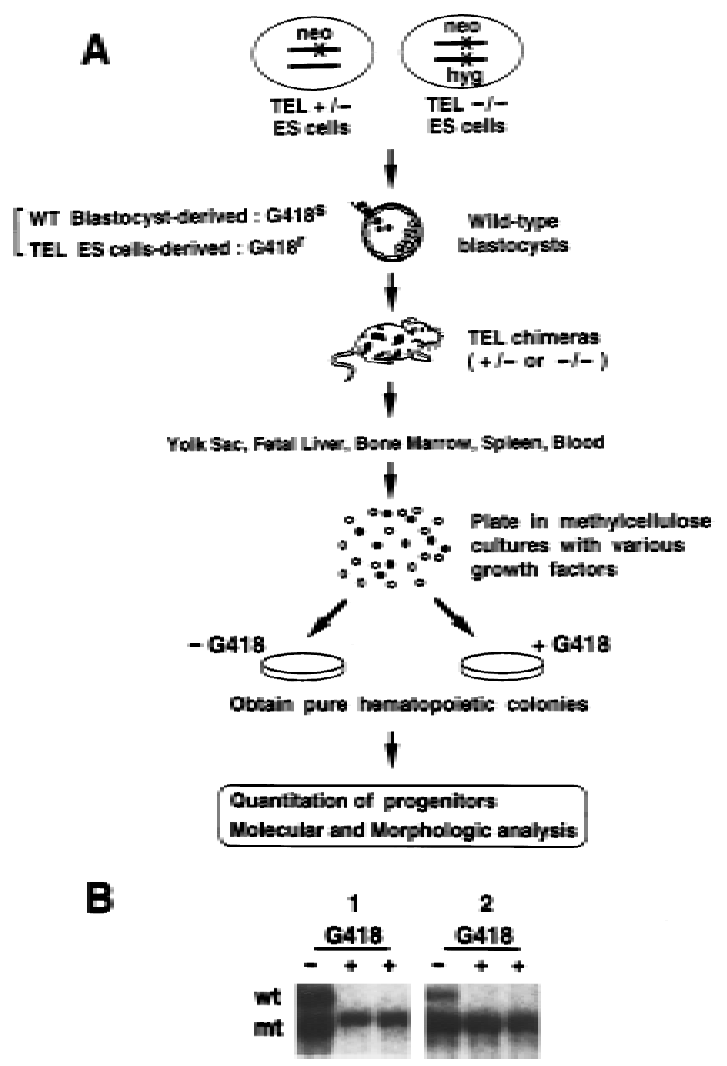

Figure 2. Assay of ES-cell-derived G418-resistant hematopoietic colonies in TEL/wild-type chimeras. (A) G418 selection strategy to distinguish hematopoietic colonies derived from wild-type (WT) or ES origins in the TEL/ wild-type chimeras (see Results). Following injection of $\mathrm{TEL}^{+1-}$ and $\mathrm{TEL}^{-1-} \mathrm{ES}$ cells into wild-type C57BL/ 6 blastocysts, single-cell suspensions are prepared from hematopoietic organs at different stages [yolk sac (E10.5), fetal liver (E14.5-E16.5), perinatal, adult]. Cells are plated in methylcellulose cultures supplemented with various growth factors, either in the presense or in the absence of G418. The numbers of colonies representing each blood-cell lineage are numerated and colonies are prepared for histological examination. (neo) N eomycin; (hyg) hygromycin; (G4185) G418 sensitive; $\left(\mathrm{G} 418^{\mathrm{r}}\right) \mathrm{G} 418$ resistant. (B) Macrophage/granulocytic colonies grown in the absence $(-)$ and in the presense $(+)$ of $\mathrm{G} 418$ (left panel, $1 \mathrm{mg} / \mathrm{ml}$; right panel, $1.5 \mathrm{mg} / \mathrm{ml} \mathrm{G} 418$, respectively) were collected from two representative (** in Table 1) TEL/ wild-type yolk-sac progenitor assays, DN As were extracted and subjected to Southern blot analysis. (wt) Wild-type allele; (mt) mutant allele. $\mathrm{N}$ ote that only targeted alleles (ES-cell-derived) were detected after selection in the presence of G418. cin-resistance gene in the targeted $\mathrm{TEL}^{+1-}$ or $\mathrm{TEL}^{-1-}$ cells (Fig. 2A). Only colonies derived from injected ES cells would be expected to survive in the presence of G418.

This strategy was validated by experiments summarized in Table 1. Macrophage/granulocyte colonies of yolk sac progenitors were obtained in the presence of G418 from embryos shown to be chimeric by Southern blot analysis. Drug-resistant colonies were not obtained from cells of nonchimeric embryos. Moreover, Southern blotting of G418-resistant colonies grown from TEL ${ }^{-1}$ / wild-type chimeras reveal ed only the targeted TEL allele (Fig. 2B). Thus, culture in the presence of G418 selects for ES-derived cells and does not permit survival of wildtype cells. Finally, the fraction of colonies surviving G418 selection cl osely parallels the degree of chimerism estimated by Southern blotting of embryonic material (Table 1). Therefore, the approach outlined in Figure 2A is a valid means of evaluating the origin of hematopoietic lineages in mouse chimeras at different stages of development.

$\mathrm{TEL}^{-1-}$ ES cells contribute to fetal liver hematopoiesis

We applied this assay to progenitors present in fetal livers of $\mathrm{TEL}^{+1-}$ and $\mathrm{TEL}^{-1-}$ chimeras. In each instance Southern blotting was used to document chimerism of varying extents in other embryonic tissues (data not shown). As summarized in Table 2, ES-derived (i.e., G418-resistant) erythroid colonies of CFU-e and BFU-e types, as well as non-red (i.e., myeloid) colonies, were observed. Colony morphologies were normal. Thus, expression of the TEL gene is not essential for fetal liver hematopoiesis. This also implies that TEL is not re quired for the intrinsic commitment and maturation of progenitors of these lineages.

Table 1. $\mathrm{TEL}^{+/-}$and $\mathrm{TEL}^{-/-} \mathrm{ES}$ cells contribute to definitive lineages at the yolk sac stage

\begin{tabular}{|c|c|c|c|c|}
\hline \multirow[b]{2}{*}{ Genotype } & \multirow[b]{2}{*}{ Chimera } & \multirow{2}{*}{$\begin{array}{c}\text { Percent } \\
\text { ES cell } \\
\text { contribution }\end{array}$} & \multicolumn{2}{|c|}{$\begin{array}{l}\text { M acrophage/granulocyte } \\
\text { colonies }\end{array}$} \\
\hline & & & -G418 & tG418 \\
\hline \multirow{5}{*}{$-1-$} & 1 & 0 & $>100$ & $* 0$ \\
\hline & 2 & 0 & $>100$ & $* 0$ \\
\hline & 3 & 50 & $84 \pm 20$ & $26 \pm 2$ \\
\hline & 4 & 60 & $168 \pm 20$ & $* * 68 \pm 2$ \\
\hline & 5 & 80 & $113 \pm 20$ & $* * 69 \pm 6$ \\
\hline \multirow{2}{*}{$H-$} & 1 & 20 & $37 \pm 3$ & $7 \pm 0$ \\
\hline & 2 & 20 & $50 \pm 5$ & $14 \pm 2$ \\
\hline
\end{tabular}

Hematopoietic progenitor assays were performed using E10.5 yolk sac cells of TEL/wild-type chimeras in the presence of macrophage/granulocyte colonies (IL-1/IL-3/G-CSF/GM-CSF). Percent ES contribution was estimated by Southern blotting. N ote that no colonies were detected in the presence of G418 in chimeras lacking ES cells contribution $(*)$. Hematopoietic colonies $(* *)$ were collected and subjected to Southern blot analysis, as shown in Fig. $2 \mathrm{~B}$. 
Table 2. $\mathrm{TEL}^{\dashv-} \mathrm{ES}$ cells contribute to fetal liver hematopoiesis

\begin{tabular}{|c|c|c|c|c|c|c|c|}
\hline \multicolumn{8}{|c|}{ Red colonies } \\
\hline \multirow[b]{2}{*}{ Chimera } & \multirow[b]{2}{*}{ Genotype } & \multicolumn{2}{|c|}{ (CFU-e) } & \multicolumn{2}{|c|}{ (BFU-e) } & \multicolumn{2}{|c|}{ N on-red Colonies } \\
\hline & & $-G 418$ & +G418 & $-G 418$ & +G418 & $-G 418$ & +G418 \\
\hline & $H-$ & $510 \pm 90$ & $190 \pm 45$ & $70 \pm 20$ & $40 \pm 5$ & $910 \pm 140$ & $190 \pm 30$ \\
\hline & $\Gamma-1-$ & $655 \pm 35$ & $\Gamma 395 \pm 50$ & $110 \pm 40$ & $-40 \pm 20$ & $750 \pm 70$ & $\ulcorner 85 \pm 10$ \\
\hline Clone 1 & $-1-$ & $610 \pm 130$ & $20 \pm 10$ & $115 \pm 35$ & $15 \pm 5$ & $925 \pm 45$ & $35 \pm 10$ \\
\hline & {$[-1-$} & $770 \pm 90$ & $55 \pm 10$ & $170 \pm 10$ & $15 \pm 5$ & $1055 \pm 165$ & $35 \pm 5$ \\
\hline Clone 2 & $-1-$ & $875 \pm 75$ & $360 \pm 45$ & $220 \pm 20$ & $90 \pm 5$ & $1200 \pm 10$ & $125 \pm 35$ \\
\hline Clone 3 & & \multicolumn{4}{|c|}{ N.D. } & $-635 \pm 35$ & {$\left[\begin{array}{l}85 \pm 15 \\
50 \pm 0\end{array}\right.$} \\
\hline
\end{tabular}

$\mathrm{OneTEL}^{+1-E S}$ clone and three independently-derived TEL ${ }^{-1-E S}$ cell clones were injected into wild-type blastocysts. Progenitor assays were performed on the resultant TEL/wild-type chimeric fetal livers (E14.5-E16.5). Erythroid (red) colonies, including CFU-e and BFU-e, and myel oid (non-red) colonies were cultured with or without G418 as in Fig. 2A. N umbers represent progenitors/10 6 fetal liver cells. (N.D.) N ot determined.

$\mathrm{TEL}^{\dashv-E S}$ cells do not contribute to bone marrow myelopoiesis and erythropoiesis

The site of hematopoiesis shifts from fetal liver to the bone marrow during the transition from intrauterine to extrauterine life. Given its dispensability for yolk sac and fetal liver hematopoiesis, a deficit in bone marrow hematopoiesis of $\mathrm{TEL}^{-1-}$ cells was not expected. However, initial studies using adult marrow cells of $>8$-weekold mice revealed that $\mathrm{TEL}^{-1-}$, but not $\mathrm{TEL}^{+-}$, cells failed to generate G418-resistant myeloid colonies in progenitor assays (Table 3A). Chimerism was indicated by ES-cell-derived agouti coat color contribution, and subsequently verified by Southern blotting in the majority of animals (see bel ow; data not shown). Further analysis revealed that the observed deficit of TEL ${ }^{-1-}$ ES-cellderived progenitors was manifest in the bone marrow by 1 week of age (Table 3A). Additional lineages were assayed to examine the extent of the deficit. TEL ${ }^{-1-}$ bonemarrow-derived mast cells (Table $3 \mathrm{~A}$ ) and megakaryocyte colonies (Table $3 \mathrm{~B}$ ) were also not observed upon G418 selection. Red blood cell contribution was assessed by hemogl obin analysis, relying on genotype differences between host and ES-derived cells. Adult red cells were exclusively of host origin in liveborn chimeras (Fig. 3). These findings indicate that TEL function is required for the production of bone marrow-derived erythroid, myeloid, mast, and megakaryocytic cells.

TEL is also required for efficient Iymphopoiesis in the adult

To address the possible involvement of TEL in Iymphopoiesis, we generated chimeras by injection of $\mathrm{TEL}^{+-}$or TEL ${ }^{-1}-$ ES cells into RAG $-2^{-1-}$ blastocysts. Because RAG-2 $2^{-1-}$ mice do not produce mature $B$ and $T$ Iymphocytes (Chen et al . 1993), examination of the number and phenotype of B and T cells in such chimeras al lows for a rapid and stringent complementation assay of Iymphoid potential.
We first examined the B- and T-cell phenotype in adult TEL/RAG-2 chimeras by FACS analysis. As shown in Figure 4A, a dramatic reduction in both the frequency and absol ute number of $\mathrm{TEL}^{-1-} \mathrm{B} 22 \mathrm{O}^{+} \mathrm{B}$ cells in the bone marrow was observed. This B-cell defect appears to lie at the progenitor level as revealed by the lack of pre-B-cell progenitors in the bone marrow assayed at 1-6 weeks of age (Table 4). $\mathrm{N}$ ote, however, that despite the paucity of $\mathrm{TEL}^{-1-} \mathrm{B} 220^{+} \mathrm{B}$ cells in the bone marrow, $\mathrm{B}^{2} 20^{+} / \mathrm{IgM}^{+}$ mature $B$ cells are present in the spl een (Fig. 4A; data not shown).

The number of TEL ${ }^{-1-} \mathrm{CD} 4^{+} \mathrm{CD} 8^{+}$immature $\mathrm{T}$ cells in the thymus was also reduced dramatically relative to that seen with $\mathrm{TEL}^{+1-}$ ES cells (Fig. 4B). As with TEL ${ }^{-1-}$ $B$ cells, the defect appears to lie at the progenitor level, as $\mathrm{TEL}^{-1-} \mathrm{CD} 25^{+}$prothymocytes fail ed to accumulate (data not shown). In addition, despite the low number of immature thymic $\mathrm{T}$ cells, mature single $\mathrm{CD} 4^{+}$or $\mathrm{CD} 8^{+} \mathrm{T}$ cells appeared to migrate to and repopulate the lymph node in the RAG-2 $2^{-1-}$ background (Fig. 4B). The total number of these mature $T$ cells was $\sim$ sixfold less than that seen in $\mathrm{TEL}^{+/-}$chimeras (Fig. 4B).

We also examined progenitors in chimeras during the transition from fetal liver to bone marrow hematopoiesis. As shown in Figure 5, FACS analysis of thymic cells of E18 TEL/RAG-2 chimeras revealed the presence of $\mathrm{TEL}^{-1-} \mathrm{CD} 4^{+} \mathrm{CD} 8^{+}$immature $\mathrm{T}$ cells in numbers approximating that of $\mathrm{TEL}^{+1-}$ cells. Thus, $\mathrm{TEL}^{-1-}$ progenitors exit the fetal liver, migrate, and home to fetal thymus, despite their paucity in the thymus after birth.

These findings indicate that TEL is not required intrinsically for the proliferation and differentiation of committed lymphoid lineages. As TEL ${ }^{-1-}$ splenic B cells and lymph node $T$ cells prol iferate in response to stimulation by LPS or anti-CD3 antibody, respectively (data not shown), TEL is also not essential for some aspects of cellular responsiveness. Because the majority of the lymphoid progenitors reside in the bone marrow during postnatal life, our data suggest, however, that TEL is required for maintaining a normal pool of Iymphoid progenitors in the bone marrow. 
Wanget al.

Table 3. TEL function is required for development of myeloid, mast cells, and megakaryocytes

\begin{tabular}{|c|c|c|c|c|c|c|c|}
\hline & era & A. $\mathrm{TEL}^{-1}$ & $\begin{array}{l}\text { not contribut } \\
\text { Macrophag }\end{array}$ & $\begin{array}{l}\text { larrow myelo } \\
\text { e colonies }\end{array}$ & & & \\
\hline genotype & age (week) & agouti & $-\mathrm{G} 418$ & tG 418 & $-\mathrm{G} 418$ & tG418 & \\
\hline & & $\ulcorner>70$ & $2240 \pm 240$ & Г $650 \pm 5$ & + & & + \\
\hline & & $\sim 50$ & $860 \pm 20$ & $370 \pm 5$ & + & & + \\
\hline & 1 & $<50$ & $660 \pm 80$ & $205 \pm 5$ & + & & + \\
\hline & & $L<50$ & $3120 \pm 340$ & L $80 \pm 0$ & + & L & + \\
\hline & 3 & {$[<50$} & $880 \pm 105$ & $280 \pm 5$ & + & & + \\
\hline$H-$ & & $\Gamma>70$ & $1285 \pm 125$ & $\Gamma 405 \pm 65$ & + & $\Gamma$ & + \\
\hline & $>$ & $>70$ & $1400 \pm 100$ & $350 \pm 5$ & + & & + \\
\hline & $>0$ & $<70$ & $260 \pm 30$ & $35 \pm 5$ & + & & + \\
\hline & & $L<70$ & $665 \pm 75$ & L $\quad 35 \pm 10$ & + & L & + \\
\hline & & {$[>70$} & $875 \pm 145$ & $5 \pm 5$ & + & $\Gamma$ & - \\
\hline & & $<50$ & $2210 \pm 390$ & 0 & + & & - \\
\hline & 1 & $<50$ & $2270 \pm 10$ & 0 & + & & - \\
\hline & & $<50$ & $2100 \pm 60$ & 0 & + & & - \\
\hline$-1-$ & & $L<50$ & $860 \pm 10$ & 0 & + & L & - \\
\hline & 3 & {$[>50$} & $1315 \pm 95$ & 0 & + & {[} & - \\
\hline & 3 & $L<50$ & $1095 \pm 45$ & 0 & + & L & - \\
\hline & & $\Gamma>70$ & $1165 \pm 165$ & 0 & + & $\Gamma$ & - \\
\hline & & $>70$ & $460 \pm 40$ & 0 & + & & - \\
\hline & $>8$ & $<70$ & $500 \pm 80$ & 0 & + & & - \\
\hline & & $L<70$ & $690 \pm 60$ & 0 & + & L & - \\
\hline
\end{tabular}

B. Lack of megakaryocytic progenitors in the bone marrows of $\mathrm{TEL}^{-1-} \rightarrow$ wild-type chimeras

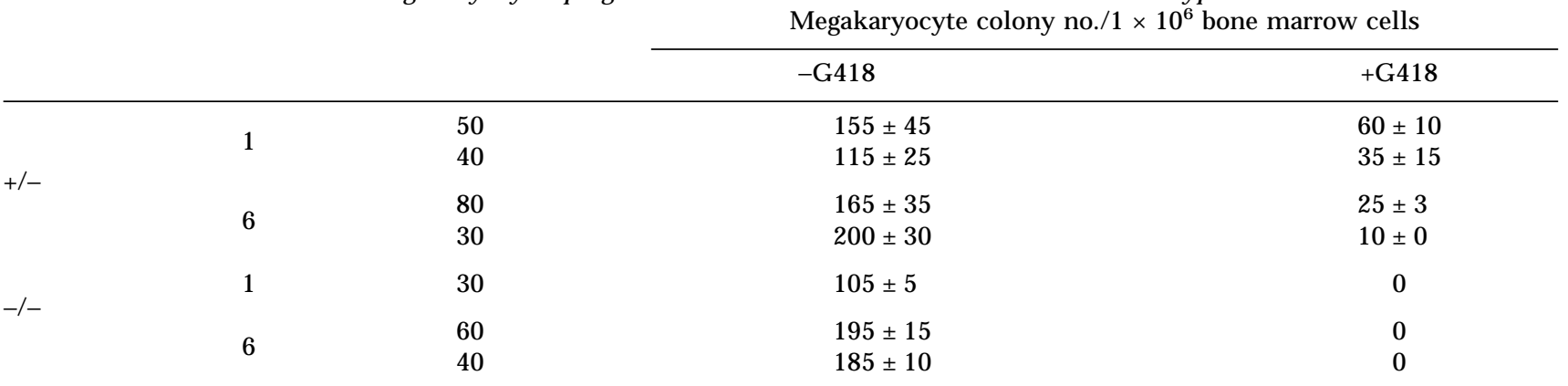

(A) Bone marrow progenitor assays were performed using TEL/wild-type chimeras with various degrees of ES cell contribution. Bone marrow cells were cultured in methylcellul ose supplemented with IL-1/IL-3/GM-CSF/G-CSF to obtain myel oid col onies indicated as no. of myeloid progenitors per $1 \times 10^{6}$ bone marrow cells. To obtain homogeneous populations of mature mast cells, $2 \times 10^{5}$ bone marrow cells $/ \mathrm{ml}$ were cultured in DMEM supplemented with $10 \%$ FCS and IL-3 for 4 weeks. In the presence of G 418 no viable cells were obtained from TEL ${ }^{-1-} /$ wild-type chimeras. Similarly, no viable cells were obtained from control wild-type C57BL/ 6 bone marrow cells upon G418 selection. (+) Mast cell growth; $(\rightarrow$ no growth.

(B) Progenitor assays were performed in the presence of kit-ligand $(K L)$ and thrombopoietin. Pure and mixed (with erythroid) megakaryocytic colonies were enumerated on day 7. The identity of megakaryocytes was confirmed by May-Grunwald-Giemsa stain and histochemical staining for acetylcholinesterase activity.

$\mathrm{TEL}^{-1-}$ ES cells do not contribute to hematopoietic organs in the adult

Because deficiency affects all lineages, our results are compatible with a critical role for TEL in the development/maintenance of HSCs or multipotential progenitor cells within the bone-marrow compartment. To examine whether such defects are reflected at the level of TEL ${ }^{-1-}$ ES-cell contribution to the hematopoi etic organs, we performed Southern blotting of tissues from young and adult mice. As shown in Figure $6 \mathrm{~A}$, both $\mathrm{TEL}^{+1-}$ and $\mathrm{TEL}^{-1-}$ cells contributed readily to nonhematopoietic tissues, including brain, heart, liver, kidney, and muscle.
In marked contrast, contribution to the hematopoietic organs was observed in TEL $\mathrm{L}^{+-}$but not $\mathrm{TEL}^{-1-}$ chimeras (Fig. 6A; data not shown). As shown by progenitor assays (Tables 1 and 2), however, TEL ${ }^{-1-}$ ES cells readily contribute to hematopoietic tissues of the embryo-yolk sac and fetal liver (Fig. 6B). These data support a restricted role for TEL in the bone marrow (Fig. 7).

Intraembryonic hematopoietic progenitors initially colonize the fetal liver, and thereafter migrate to other hematopoietic organs (spleen, thymus, and bone marrow). In the adult, the bone marrow is the primary source of multipotential progenitors, which then seed other hematopoietic sites via the circulation. TEL function 

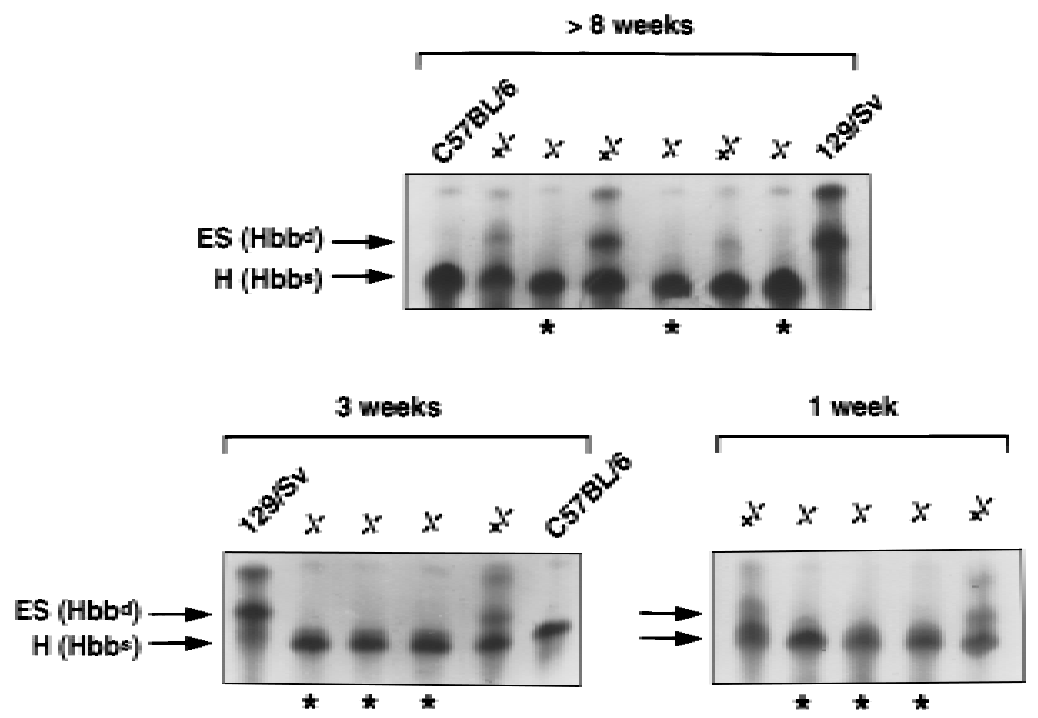

Figure 3. $\mathrm{TEL}^{\dashv-} \mathrm{ES}$ cell progneitors do not contribute to mature erythroid lineages in chimeras. Red blood cells from young and adult chimeric mice were subject to hemoglobin analysis. [H $\left(\mathrm{Hbb}^{\mathrm{s}}\right)$ ] Specific for host (C 57BL/6) blastocyst cells; [ES $\left(\mathrm{H} \mathrm{bb}^{\mathrm{d}}\right)$ ] specific for ES (129/Sv) cells. (*) Lack of adult $\beta$-hemoglobin contribution from $\mathrm{TEL}^{-1-}$ EScell-derived chimeras. might be required in one, or multiple, processes, including migration and/or homing from the fetal liver to other sites, or progenitor survival/proliferation within the marrow microenvironment. Although cellular migration cannot be studied conveniently in chimeras, the presence of low numbers of $\mathrm{TEL}^{-1-}$ hematopoietic progenitors in the bone marrow, spleen, and liver of newborn animals and in the spleen and liver of E18 embryos (data not shown) suggests that $\mathrm{TEL}^{-1-}$ hematopoi etic cells initially seed sites of hematopoietic activity, but in the absence of stable colonization of the bone-marrow microenvironment, hematopoiesis is not sustained.

\section{Discussion}

The TEL gene is involved in leukemias of both myeloid and lymphoid origins (Golub et al. 1997). During early embryonic development TEL is required for yolk-sac angiogenesis and for survival of several cell types (Wang et al. 1997). Here we have used mouse chimera analysis (Pevny et al. 1991; Porcher et al. 1996) to address additional roles for TEL in later development, specifically within hematopoiesis. Our studies reveal a unique requirement for TEL in establishing stable bone-marrow hematopoiesis in early postnatal life and in the adult (Fig. 7). The specificity of TEL loss of function for hematopoiesis in this site, as contrasted with other sites during development, points to the existence of novel regulatory pathways in bone-marrow HSCs or progenitors. Moreover, our results may relate to the pathogenesis of childhood pre-B leukemia associated with TEL/AML1 translocations and loss of heterozygosity at the TEL Iocus.

TEL serves a critical, nonredundant function in bone-marrow hematopoiesis

The expression of the TEL locus in hematopoietic cells, taken together with its rearrangement in leukemia, hinted at a potential role for TEL in hematopoiesis. Our prior data relying on in vitro differentiation of $\mathrm{TEL}^{-1-} \mathrm{ES}$ cells and progenitor assay of $\mathrm{TEL}^{-1-}$ yolk-sac progenitor cells, however, demonstrated that TEL function is dispensable for the committment and differentiation of erythroid-myeloid lineages. This conclusion is confirmed by the studies reported here. The presence of a low number of otherwise normal TEL ${ }^{-1-} B$ and $T$ Iymphocytes in $\mathrm{TEL}^{-1-} / \mathrm{RAG}-2^{-1-}$ chimeras further indicates that $\mathrm{TEL}$ is not essential for development of lymphoid cells.

Whereas TEL is dispensable for the intrinsic differentiation of blood lineages, however, it is required for in vivo hematopoi esis within the bone marrow. This is an unexpected finding that points to critical differences in the nature of hematopoi etic HSCs (or progenitors) that develop within different anatomic sites or differences in the responses of these cells to varying microenvironments (see bel ow).

The bone marrow microenvironment is comprised of diverse cell types, including reticular fibroblasts, adipocytes, macrophages, endothelial cells, and extracellular matrix (Mayani et al. 1992; Papayannopoulou and Craddock 1997). Because our results are derived from the analysis of multiple chimeras of varying contribution of host to the microenvironment, we infer that the bonemarrow defect is cell-autonomous and hematopoieticcell specific. Our findings, however, do not exclude additional functions of TEL specific to cells of the microenvironment, as these would not be detected in our assays. It might also be argued that the hematopoietic defects reflect unknown, TEL-independent genetic al terations in the TEL ${ }^{-1}$ ES clones that might impair contribution of ES cells to hematopoietic, but not other, compartments in chimeras. This explanation is highly unlikely for at least two reasons. First, as controls for the experiments, we have used $\mathrm{TEL}^{+/-} \mathrm{ES}$ clones that were selected in parallel with $\mathrm{TEL}^{-1-}$ clones. In numerous experiments, we document that $\mathrm{TEL}^{+-}$- clones contribute efficiently to the hematopoietic system of chimeras (see Table 3A). Second, the temporal appearance of the he- 
A

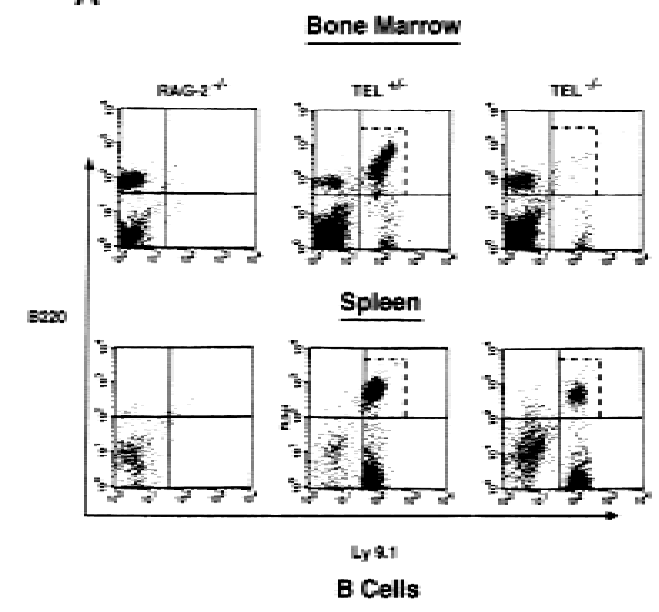

B

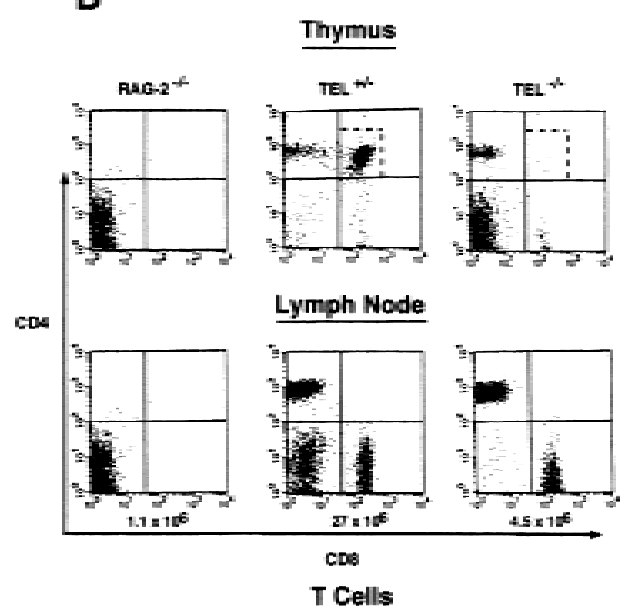

Figure 4. $\mathrm{TEL}^{-1-} \mathrm{ES}$-derived cells do not reconstitute efficiently lymphoid lineages in RAG-2 ${ }^{-1-}$ chimeras. Flow cytometry was performed on hematopoietic compartments of the TEL/RAG-2 chimeras. Anti-B220 antibody was used as B-cell marker for bone marrow and spleen cells. Anti-Ly 9.1 antibody distinguishes ES-derived from RAG-2 ${ }^{-1-}$ blastocyst-derived lymphocytes (the latter are Ly9.1-). (A) Anti-CD4 and CD8 antibodies were used as $\mathrm{T}$-cell markers for thymus and lymphnode cells. (B) The total numbers of Iymph-node $T$ cells are indicated. The dotted rectangles highlight the differences in the frequency of reconstituting lymphocytes between the $\mathrm{TEL}^{\mathrm{H}-}$ and $\mathrm{TEL}^{-1-}$ ES-cell-derived chimeras.

matopoi etic defect is remarkable in its onset. Contribution of $\mathrm{TEL}^{-1-}$ ES cells to fetal liver progenitors is detected readily at E14.5-16, whereas contri bution to bonemarrow progenitors is virtually absent just several days later. We conclude that the failure of $\mathrm{TEL}^{-1-}$ hematopoietic progenitors to achieve stable colonization of the bone marrow reflects a nonredundant, selective, and cell-autonomous function for TEL.

Possible mechanisms for bone-marrow hematopoietic defects in the absence of TEL

The establishment of bone-marrow hematopoiesis ne- cessitates migration of HSCs (or progenitors) from the fetal liver (or other intraembryonic sites) and subsequent retention, survival, and proliferation of these cells within the marrow microenvironment. The interaction of the microenvironment with hematopoietic cells is critical for blood-cell production. Stroma provides a solid support for hematopoiesis, in part facilitating availability to membrane-localized growth factors. Hematopoietic site-restricted interactions may al so be inferred from experiments in sheep indicating that liver-derived fetal progenitors home preferentially to fetal bone marrow (Zanjani et al. 1993).

Adhesive interactions of hematopoietic cells with stroma and cells of the mi croenvironment are important in vivo (Coulombel et al. 1997; Papayannopoulou and Craddock 1997). Some of these are mediated by integrin interactions with their respective ligands and are critical in vivo (Hynes 1996). For example, migration or homing of progenitors to the fetal liver requires $\beta 1$ integrin ( $\mathrm{Hir}$ sch et al . 1996). M aintenance of postnatal lymphopoiesis is dependent on expression $\alpha 4$ integrin (A rroyo et al. 1996). Moreover, integrins, notably $\alpha 4 \beta 1, \alpha 5 \beta 1$ and their cognate ligands, V-CAM and fibronectin, have been shown to be necessary for proper cell-cell and/or cellextracellular matrix adhesion in the development of various tissues, including the hematopoietic system (Hynes 1996; Papayannopoulou and Craddock 1997). Further analysis of the $\alpha 4$ knockout reveals the existence of hematopoietic defects outsi de the lymphoid compartment (A. Arroyo and R. Hynes, pers. comm.). This might recommend $\alpha 4$ as a candidate target gene for TEL. How-

Table 4. Lack of pre-B cell progenitors in the bone marrows of $\mathrm{TEL}^{-1-} \rightarrow$ wild-type chimeras

\begin{tabular}{|c|c|c|c|c|}
\hline \multicolumn{2}{|c|}{ Chimera } & \multirow{3}{*}{$\begin{array}{l}\text { Percent } \\
\text { agouti }\end{array}$} & \multirow{2}{*}{\multicolumn{2}{|c|}{$\begin{array}{l}\text { Pre-B cell colony no./ } \\
1 \times 10^{6} \text { bone marrow cells }\end{array}$}} \\
\hline & & & & \\
\hline genotype & (weeks) & & -G418 & tG 418 \\
\hline \multirow{3}{*}{$H-$} & 1 & $\begin{array}{l}80 \\
15\end{array}$ & $\begin{array}{l}345 \pm 50 \\
640 \pm 40\end{array}$ & $\begin{array}{r}140 \pm 5 \\
4 \pm 1\end{array}$ \\
\hline & 2 & $\begin{array}{l}80 \\
60\end{array}$ & $\begin{array}{l}895 \pm 35 \\
775 \pm 75\end{array}$ & $\begin{array}{c}203 \pm 23 \\
71 \pm 8\end{array}$ \\
\hline & 6 & $\begin{array}{l}80 \\
30\end{array}$ & $\begin{array}{l}307 \pm 13 \\
285 \pm 25\end{array}$ & $\begin{array}{l}69 \pm 6 \\
19 \pm 1\end{array}$ \\
\hline \multirow{3}{*}{$-1-$} & 1 & $\begin{array}{l}40 \\
40 \\
30\end{array}$ & $\begin{array}{l}480 \pm 0 \\
398 \pm 38 \\
210 \pm 25\end{array}$ & $\begin{array}{l}0 \\
0 \\
0\end{array}$ \\
\hline & 2 & $\begin{array}{l}60 \\
40 \\
40\end{array}$ & $\begin{aligned} 935 & \pm 5 \\
1060 & \pm 40 \\
595 & \pm 65\end{aligned}$ & $\begin{array}{l}0 \\
0 \\
0\end{array}$ \\
\hline & 6 & $\begin{array}{l}60 \\
40\end{array}$ & $\begin{array}{l}370 \pm 0 \\
333 \pm 47\end{array}$ & $\begin{array}{l}0 \\
0\end{array}$ \\
\hline
\end{tabular}

Pre-B cell progrenitor assays were performed in 1- to 6-week-old chimeric mice. Bone marrow cells $\left(2 \times 10^{5}\right)$ were cultured in methylcellulose supplemented with IL-7 (H3630, Stem Cell Technology), and pre-B colonies were enumerated on day 10. N umbers represent pre-B progenitors $/ 1 \times 10^{6}$ bone marrow cells. 


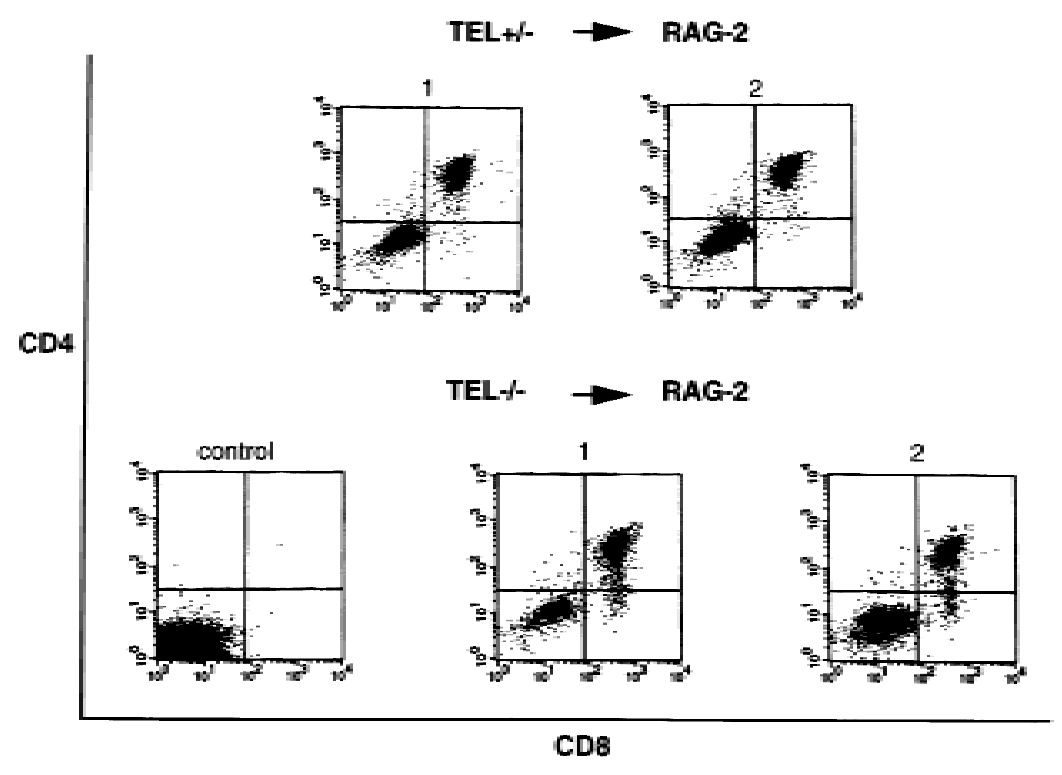

Figure 5. $\mathrm{TEL}^{-1-} \mathrm{ES}$ cells contribute to thymic $\mathrm{T}$ cells prior to birth. TEL ${ }^{+1-}$ and $\mathrm{TEL}^{-1-} \mathrm{ES}$ cells were injected into RAG-2-1- blastocysts, and flow cytometry of thymocytes was performed at E18. The majority of the thymocytes at E18 are $\mathrm{CD} 4^{+} \mathrm{CD} 8^{+}$. Representative FACS analysis from 2 $\mathrm{TEL}^{+1-}$ and $2 \mathrm{TEL}^{-1-}$ chimeras are shown. The control represents an embryo that lacked detectable ES cell contribution. ever, our preliminary analysis demonstrates ostensibly normal expression of $\alpha 4$ in TEL ${ }^{-1}$ fetal liver cells. M oreover, undifferentiated TEL ${ }^{-1-}$ ES cells bind fibronectin and $\mathrm{V}-\mathrm{CAM}$, cognate ligands for $\alpha 4$ integrin (data not shown). Thus, if TEL regulates the expression of integrins, or other adhesive molecules, their identity is as yet unknown.

Beyond mere adhesion of HSC s or progenitors to marrow stroma elements, the responses of cells to these interactions and to other stimuli of the microenvironment are likely to be critical in stable colonization and subsequent blood-cell production. TEL function might be essential in one (or multiple) aspect(s) of these pathways. Regardless of the specific target genes in HSCs or progenitors, it seems likely that TEL serves critical functions in the response of HSCs or progenitors to the bonemarrow microenvironment.

\section{Speculations regarding TEL function and leukemia}

In instances of leukemias in which gene fusions are expressed, translocations are undoubtedly inciting genetic events (Rabbitts 1994). Indeed, recent evidence indicates that at least in one variety of pediatric leukemia, translocation between the MLL and AF4 loci occurs antenatally (Gale et al. 1997). Rearrangement of the TEL and AML1 loci may have a similarly early origin in development (Ford et al. 1998). If such somatic events precede onset of evident disease by several years, it seems highly probable that secondary genetic events contribute to its evolution and progression. Such hypotheses conform to the prevailing view that oncogenesis is a multistep process (N owell 1976).

The TEL locus was discovered through its fusion with the PDGF $\beta$ R gene in chronic myelomonocytic leukemia $(C M M L)$, and has been shown subsequently to be rearranged with the $C-a b l, ~ J A K ~ 2$, and $A M L-1$ loci in $C M M L$, T-ALL, and pre-B-ALL (see Golub et al. 1997). In the TEL
A
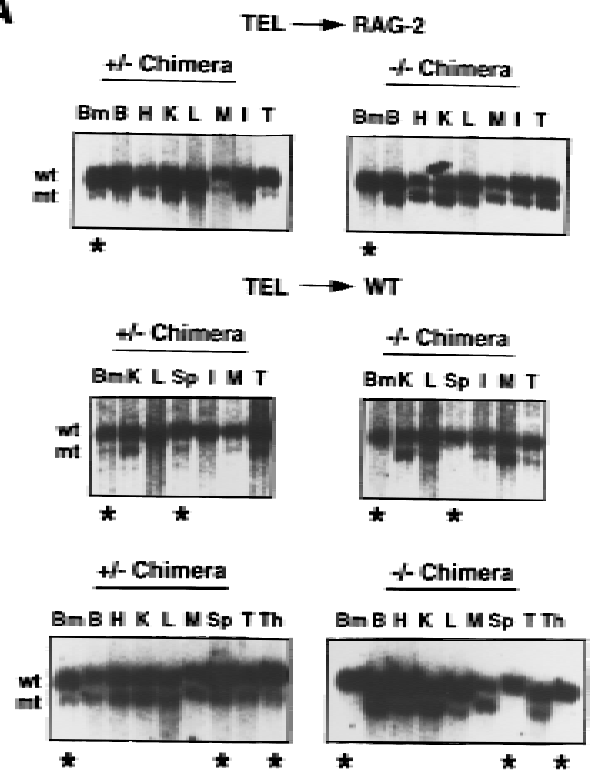

B

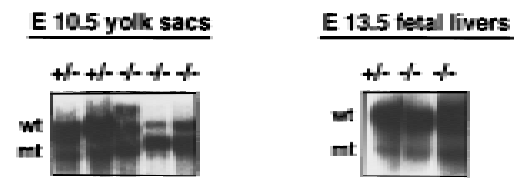

Figure 6. $\mathrm{TEL}^{-1-} \mathrm{ES}$ cells fail to contribute to adult hematopoietic tissues in chimeras. Southern blots were performed using DN As of various adult tissues from $\mathrm{TEL}^{+1-}$ or $\mathrm{TEL}^{-1-} \mathrm{ES}-$ cell-derived chimeras in the RAG-2 or wild-type (WT) backgrounds (A) and hematopoietic cells derived from yolk sacs or fetal livers (B). (wt) Wild-type alleles; (mt) mutant alleles; (Bm) bone marrow; (B) brain; $(\mathrm{H})$ heart; $(\mathrm{K})$ kidney; (L) liver; $(\mathrm{M})$ muscle; (I) intestine; (Sp) spleen; $(T)$ tail; (Th) thymus; $\left({ }^{*}\right)$ hematopoietic tissues (BM, Sp, and Th). 
Wang et al.

Embryonicffetal hematopoiesis

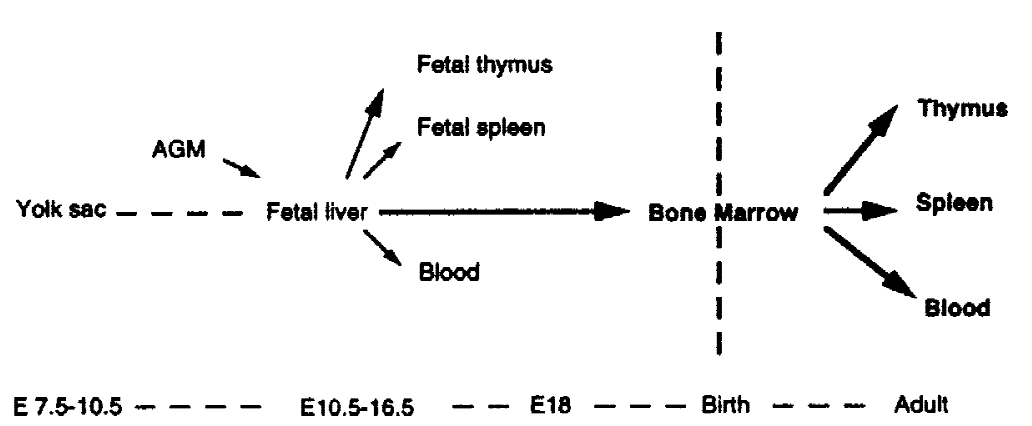

Figure 7. The requirement for TEL in the devel opment of the hematopoi etic system. Arrows depict the colonization routes of $\mathrm{HSC} /$ multipotent progenitors.

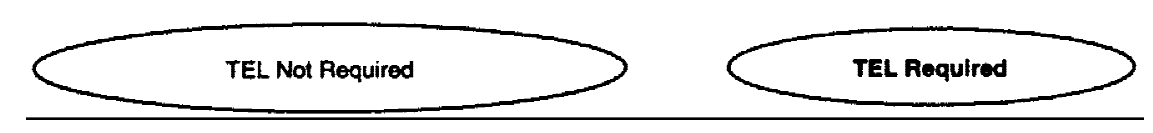

fusions with PDGF $\beta$ R, c-abl, and JAK2, TEL-induced oligomerization results in constitutive activation of downstream-signaling pathways (Carroll et al . 1996; Lacronique et al. 1997). Such is not the case for the TEL/ AML1 fusion protein, which is presumed to act by different mechanisms, perhaps including alteration of AM L1 function, which is essential on its own for definitive hematopoi esis (Okuda et al. 1996; Wang et al. 1996). A distinctive feature of TEL/AML1-associated leukemia is nearly invariant loss of heterozygosity at chromosome $12 p$, which includes the site of the TEL locus, as well as that of the cyclin inhibitor p27(Kipl) (Sato et al. 1995; Stegmaier et al. 1995; Kim et al. 1996; Raynaud et al. 1996). Expression of normal TEL mRNA in cells of rare patients in early samples, but not at later times, is consistent with TEL loss serving as a secondary genetic "hit" in disease progression (Kim et al. 1996). Based on the novel consequences of the absence of TEL for hematopoiesis demonstrated here, we speculate regarding their implications for evolution of childhood pre-B-TELAM L1-associated leukemia.

The inability of TEL ${ }^{-1}$ HSCs (or progenitors) to stably colonize the bone marrow might reflect defective adhesion or defective adhesion-mediated cellular responses. Studies, largely in the context of Phildelphia ${ }^{+}-C M L$, have suggested that leukemic cells are impaired in both respects (Verfaillie 1997). Leukemic progenitors may circulate prematurely in the blood, and also proliferate excessively because of altered adhesive properties. Thus, if TEL regulates adhesion receptors or pathways responsive to adhesion, its loss would predict altered behavior of leukemic progenitors. Alternatively, TEL may mediate aspects of adhesion-independent cellular responses to the bone-marrow microenvironment. On one hand, our finding that loss of TEL in otherwise normal hematopoietic progenitors cripples their capacity for effective hematopoiesis in the bone marrow appears counterintuitive as a potential contributing factor in the pathogenesis of TEL/AML1 pre-B-cell leukemia. If we postulate, however, that unique properties of the TEL/AML1 fusion protein rescue otherwise doomed $\mathrm{TEL}^{-1-} \mathrm{HSCS}$ (or a sub- set of progenitors) in the bone-marrow microenvironment for subsequent survival, proliferation, and competition with normal progenitors, such apparent discrepancies may be reconciled. In principle, these aspects of the pathogenesis of childhood pre-B-cell leukemia might be addressed with suitable genetic manipulations in the mouse. It seems likely that the bone marrow-restricted deficit of $\mathrm{TEL}^{-1-}$ hematopoietic cells described here is relevant to the evolution of this form of leukemia.

\section{Materials and methods}

Blotting and in situ hybridization

Northern and Southern blotting were described previously (Wang et al. 1997). In situ hybridization was performed with digoxigenin-11-UTP (Boehringer-M annhei $\mathrm{m}$ )-label ed riboprobes generated from a 550-bp EcoRI-Eco47III fragment spanning the 5' TEL-untranslated region (Wang et al. 1997).

\section{Generation of chimeras}

$\mathrm{TEL}^{+1-}$ and $\mathrm{TEL}^{-1-} \mathrm{ES}$ clones were injected into $\mathrm{C} 57 \mathrm{BL} / 6$ or RAG-2 $2^{-1-}$ blastocysts (Chen et al. 1993). Bone marrow, thymus, spleen, or lymph-node cells of E18, newborn or 1-16 weeks old mice were collected for hematopoi etic progenitor assay or FACS analysis. Internal organs were used for extraction of DNA. Chimerism was assessed by agouti coat-color contribution in the adult mice and/or by Southern blot analysis (Porcher et al. 1996). Two independent clones each of $\mathrm{TEL}^{+/-}$and $\mathrm{TEL}^{-1-} \mathrm{ES}$ cells were used for injections. Data on the myeloerythroid lineages were derived from the study of 7-14 chimeras. For RAG$2^{-1-}$ blastocyst experiments, $7 \mathrm{TEL}^{+1-}$, and $10 \mathrm{TEL}^{-1-}$ chimeras were analyzed.

\section{Hematopoietic progenitor assays from chimeric mice}

Yolk sac, fetal liver, spleen, and bone-marrow progenitor assays were performed as described (Porcher et al. 1996; Wang et al. 1997). Cells $\left(1-2 \times 10^{5}\right)$ were plated into methylcellulose medium supplemented with various growth factors (Porcher et al. 1996) either in the presence $(1.5 \mathrm{mg} / \mathrm{ml})$ or absence of $\mathrm{G} 418$. Pre-B-cell colony assays were performed in the presence of IL7-containing methylcellulose (Stem Cell Technologies). 
Hemoglobin assay

Hemoglobin analysis was performed as described (Porcher et al. 1996).

\section{FACS analysis}

Preparation and staining of Iymphoid cells were performed as described (Porcher et al. 1996).

\section{Acknowledgments}

We thank Kerrianne Cunniff for technical assistance. T.R.G. is a recipient of a Burroughs Well come Fund Career A ward in the Biomedical Sciences. D.G.G., F.W.A., and S.H.O. are Investigators of the Howard Hughes Medical Institute. These studies were supported in part by a Center of Excellence in Molecular Hematology award of the $\mathrm{N}$ ational Institute of Diabetes and Digestion and Kidney Diseases, $\mathrm{N}$ ational Institutes of Health.

The publication costs of this article were defrayed in part by payment of page charges. This article must therefore be hereby marked "advertisement" in accordance with 18 USC section 1734 solely to indicate this fact.

\section{References}

Arroyo, A., J.T. Yang, H. Rayburn, and R.O. Hynes. 1996. Differentiation requirement for $\alpha 4$ integrins during fetal and adult hematopoiesis. Cell 85: 997-1008.

Carroll, M., M.H. Thomasson, G.F. Barker, T.R. Golub, and D.G. Gilliland. 1996. The TEL/PDGFR $\beta$ fusion in CMML is a transforming protein that self-associates and activates PDGFR $\beta$ kinase-dependent signaling pathways. Proc. Natl. Acad. Sci. 93: 14845-14850.

Chen, J., R. Lansford, V. Stewart, F. Young, and F.W. Alt. 1993. RAG-2-deficient blastocyst complementation: An assay of gene function in lymphocyte development. Proc. Natl. Acad. Sci. 90: 4528-4532.

Coulombel, L., I. Auffray, M.H. Gaugler, and M. Rosenblatt. 1997. Expression and function of integrins on hematopoietic progenitor cells. Acta Haematol. 97: 13-21.

Delassus, S. and A. Cumano. 1996. Circulation of hematopoietic progenitors in the mouse embryo. Immunity 4: 97-106.

Ford, A.M., C.A. Bennett, C.M. Price, M.C.A. Bruin, E.R.V. Wering, and M. Greaves. 1998. Fetal origins of the TEL-AML1 fusion gene in identical twins with leukemia. Proc. Natl. Acad. Sci. 95: 4584-4588.

Gale, K.B., A.M. Ford, R. Repp, A. Borkhardt, C. Keller, O.B. Eden, and M.F. Greaves. 1997. Backtracking leukemia to birth: Identification of clonotypic gene fusion sequences in neonatal blood spots. Proc. Natl. Acad. Sci. 94: 1395013954.

Godin, I.E., J.A. Garcia-Porrero, A. Coutinho, F. DieterlenLievre, and M.A.R. Marcos. 1993. Para-aortic splanchnopleura from early mouse embryos contains Bla cell progenitors. Nature 364: 67-70.

Golub, T.R., G.F. Barker, M. Lovett, and D.G. Gilliland. 1994. Fusion of PDGF receptor $\beta$ to a novel ets-like gene, tel, in chronic myel omonocytic leukemia with $\mathrm{t}(5 ; 12)$ chromosomal translocation. Cell 77: 307-316.

Golub, T.R., G.F. Barker, S.K. Bohlander, S. Hiebert, D.C. Ward, P. Bray-Ward, E. Morgan, S.C. Raimondi, J.D. Rowley, and D.G. Gilliland. 1995. Fusion of the TEL gene on 12p13 to the AML1 gene on 21q22 in acute lymphoblastic leukemia. Proc. Natl. Acad. Sci. 92: 4917-4921.
Golub, T.R., A. Goga, G.F. Barker, D.E. Afar, J. M cLaughlin, S.K. Bohlander, J.D. Rowley, O.N. Witte, and D.G. Gilliland. 1996. Oligomerization of the ABL tyrosine kinase by the Ets protein TEL in human leukemia. Mol. Cell. Biol. 16: 41074116.

Golub, T.R., G.F. Barker, K. Stegmaier, and D.G. Gilliland. 1997. The TEL gene contributes to the pathogenesis of myeloid and lymphoid leukemias by diverse molecular genetic mechanisms. Curr. Top. Microbiol. Immunol. 220: 67-79.

Hirsch, E., A. Iglesias, A.J. Potocnik, U. Hartmann, and R. Fassler. 1996. Impaired migration but not differentiation of haematopoietic stem cells in the absence of $\beta 1$ integrins. Nature 380: 171-175.

Hynes, R.O. 1996. Targeted mutations in cell adhesion genes: What have we learned from them? Dev. Biol. 180: 402-412.

Kennedy, M., M. Firpo, K. Choi, C. Wall, S. Robertson, N. Kabrun, and G. Keller. 1997. A common precursor for primitive erythropoiesis and definitive hematopoiesis. Nature 386: 488-493.

Kim, D.-H., R.L. Moldwin, C. Vignon, S.K. Bohlander, Y. Suto, L. Giordano, R. Gupta, S. Fears, G. Nucifora, J.D. Rowley, and S.D. Smith. 1996. TEL-AML1 translocations with TEL and CDKN 2 inactivation in acute lymphoblastic leukemia cell lines. Blood 88: 785-794.

Lacronique, V., A. Boureux, V.D. Valle, H. Poirel, C.T. Quang, M. Mauchauffe, C. Berthou, M. Lessard, R. Berger, J. Ghysdael, and O.A. Bernard. 1997. A TEL-JAK2 fusion protein with constitutive kinase activity in human leukemia. Science 278: 1309-1312.

Mayani, H., L.J. Guilbert, and A. Jamowska-Wieczorek. 1992. Biology of the hematopoietic microenvironment. Eur. J. Haematol. 49: 225-233.

M cLean, T.W., S. Ringold, D. N euberg, K. Stegmaier, R. Tantravahi, J. Ritz, H.P. Koeffler, S. Takeuchi, J.W.G. Janssen, T. Seriu, C.R. Bartram, S.E. Sallan, D.G. Gilliland, and T.R. Golub. 1996. TEL/AML-1 dimerizes and is associated with a favorable outcome in childhood acute lymphoblastic leukemia. Blood 88: 4252-4258.

Medvinsky, A. and E. Dzierzak. 1996. Definitive hematopoiesis is autonomously initiated by the AGM region. Cell 86: 897906.

Medvinsky, A.L., N.L. Samoylina, A.M. Muller, and E.A. Dzierzak. 1993. An early pre-liver intraembryonic source of CFU-S in the developing mouse. Nature 364: 64-66.

Nowell, P.C. 1976. The clonal evolution of tumor cell populations. Science 194: 23-28.

Okuda, T., J.v. Deursen, S.W. Hiebert, G. Grosveld, and J.R. Downing. 1996. AML1, the target of multiple chromosomal translocations in human leukemia, is essential for normal fetal liver hematopoiesis. Cell 84: 321-330.

Orkin, S.H. 1996. Development of the hematopoietic system. Curr. O pin. Genet. Devel. 6: 597-602.

Papadopoulos, P., S.A. Ridge, C.A. Boucher, C. Stocking, and L.M. Wiedemann. 1995. The novel activation of ABL by fusion to an ets-related gene, TEL. Cancer Res. 55: 34-38.

Papayannopoulou, T. and C. Craddock. 1997. Homing and trafficking of hemopoietic progenitor cells. Acta Haematol. 97: 97-104.

Peeters, P., S.D. Raynaud, J. Cools, I. Wlodarska, J. Grosgeorge, P. Philip, F. M onpoux, L.V. Rompaey, M. Baens, H.V. Berghe, and P. Marynen. 1997. Fusion of TEL, the ETS-variant gene 6 (ETV6), to the receptor-associated kinase JAK2 as a result of $\mathrm{t}(9 ; 12)$ in a lymphoid and $\mathrm{t}(9 ; 15 ; 12)$ in a myel oid leukemia. Blood 90: 2535-2540.

Pevny, L., M.C. Simon, E. Robertson, W.H. Klein, S.-F. Tsai, V. D'A gati, S.H. Orkin, and F. Costantini. 1991. Erythroid dif- 


\section{Wang et al.}

ferentiation in chimeric mice blocked by a targeted mutation in the gene for transcription factor GATA-1. Nature 349: 257-260.

Porcher, C., W. Swat, K. Rockwell, Y. Fujiwara, F.W. Alt, and S.H. Orkin. 1996. The T-cell leukemia oncoprotein SCL/ tal-1 is essential for development of all hematopoietic lineages. Cell 86: 47-57.

Rabbitts, T.H. 1994. Chromosomal translocations in human cancer. Nature 372: 143-149.

Raynaud, S., H. Cave, M. Baens, C. Bastard, V. Cacheux, J. Grosgeorge, C. Guidal-Giroux, C. Guo, E. Vilmer, P. Marynen, and B. Grandchamp. 1996. The 12;21 translocation involving TEL and deletion of the other TEL allele: Two frequently associated al terations found in childhood acute lymphoblastic leukemia. Blood 87: 2891-2899.

Robb, L., N.J. Elwood, A.G. Elefanty, F. Kontgen, R. Li, L.D. Barnett, and C.G. Begley. 1996. The scl gene product is required for the generation of all hematopoi etic lineages in the adult mouse. EMBO J. 15: 4123-4129.

Romana, S.P., M. M auchauffe, M. Le Coniat, I. Chumakov, D. Le Paslier, R. Berger, and O.A. Bernard. 1995. The t(12;21) of acute lymphoblastic leukemia results in a tel-AML1 gene fusion. Blood 85: 3662-3670.

Sato, Y., Y. Suto, J. Pietenpol, T.R. Golub, D.G. Gilliland, E.M . Davis, M.M. Le Beau, J.M. Roberts, B. Vogel stein, J.D. Rowley, and S.K. Bohlander. 1995. TEL and KIP1 define the smallest region of deletions on 12 p13 in hematopoietic malignancies. Blood 86: 1525-1533.

Shivdasani, R.A. and S.H. Orkin. 1996. The transcriptional control of hematopoiesis. Blood 87: 4025-4039.

Shurtleff, S.A., A. Buijs, F.G. Behm, J.E. Rubnitz, S.C. Raimondi, M.L. Hancock, G.C. Chan, C.H. Pui, G. Grosveld, and J.R. Downing. 1995. TEL/AML1 fusion resulting from a cryptic $t(12 ; 21)$ is the most common genetic lesion in pediatric $A L L$ and defines a subgroup of patients with an excellent prognosis. Leukemia 9: 1985-1989.

Stegmaier, K., S. Pendse, G.F. Barker, P. Bray-Ward, D.C. Ward, K.T. Montgomery, K.S. Krauter, C. Reynolds, J. Sklar, M. Donnelly, S.K. Bohlander, J.D. Rowley, S.E. Sallan, D.G. Gilliland, and T.R. Golub. 1995. Frequent loss of heterozygosity at the TEL gene locus in acute lymphoblastic leukemia of childhood. Blood 86: 38-44.

Veiby, O.P., A.A. Mikhail, and H.R. Snodgrass. 1997. Growth factors and hematopoietic stem cells. Hematol. Oncol. Clin. N. Am. 11: 1173-1184.

Verfaillie, C.M. 1997. Stem cells in chronic myelogenous leukemia. Hematol. Oncol. Clin. N. Am. 11: 1079-1114.

Wang, Q., T. Stacy, M. Binder, M. Marin-Padilla, A.H. Sharpe, and N.A. Speck. 1996. Disruption of the Cbfa2 gene causes necrosis and hemorrhaging in the central nervous system and blocks definitive hematopoiesis. Proc. Natl. Acad. Sci. 93: 3444-3449.

Wang, L.C., F. Kuo, Y. Fuji wara, D.G. Gilliland, T.R. Golub, and S.H. Orkin. 1997. Yolk sac angiogenic defect and intra-embryonic apoptosis in mice lacking the Ets-rel ated factor TEL. EMBO J. 16: 4374-4383.

Yoder, M.C., K. Hiatt, P. Dutt, P. Mukherjee, D.M. Bodine, and D. Orlic. 1997. Characterization of definitive lymphohematopoietic stem cells in the day 9 murine yolk sac. Immunity 7: 335-344.

Yu, B.D., J.L. Hess, S.E. Horning, G.A.J. Brown, and S.J. Korsmeyer. 1995. Altered Hox expression and segmental identity in MII-mutant mice. Nature 378: 505-508.

Zanjani, E.D., J.L. Ascensao, and M. Tavassoli. 1993. Liver-derived fetal hematopoietic stem cells selectively and preferentially home to fetal bone marrow. Blood 81: 399-404. 


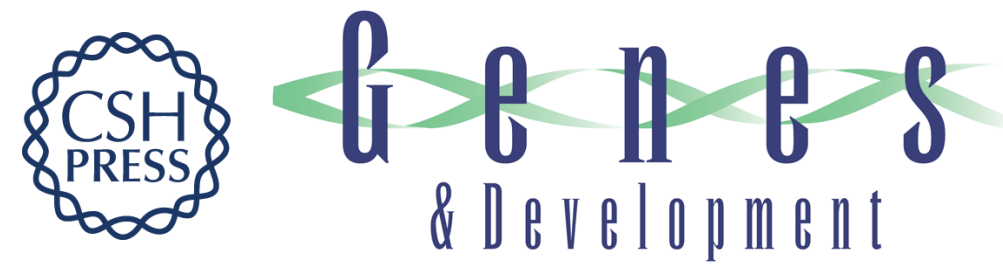

\section{The TEL/ETV6 gene is required specifically for hematopoiesis in the bone marrow}

Li Chun Wang, Wojciech Swat, Yuko Fujiwara, et al.

Genes Dev. 1998, 12:

Access the most recent version at doi:10.1101/gad.12.15.2392

References

This article cites 44 articles, 20 of which can be accessed free at: http://genesdev.cshlp.org/content/12/15/2392.full.html\#ref-list-1

\section{License}

Email Alerting

Receive free email alerts when new articles cite this article - sign up in the box at the top Service right corner of the article or click here.

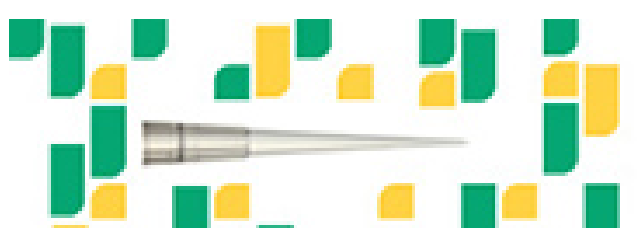

Focused on your science. 